\title{
Recurrent High Grade Burkitt-Like Lymphoma
}

National Cancer Institute

\section{Source}

National Cancer Institute. Recurrent High Grade Burkitt-Like Lymphoma. NCI Thesaurus.

Code C5004.

The reemergence of high grade B-cell lymphoma Burkitt-like lymphoma after a period of remission 